\title{
U-Shaped Relationship Between Functional Outcome and Serum Uric Acid in Ischemic Stroke
}

\author{
Yimin Yang ${ }^{\mathrm{a}}$ Ying Zhang ${ }^{\mathrm{b}}$ Yanhua Li ${ }^{\mathrm{a}} \quad$ Lili Ding $^{\mathrm{a}} \quad$ Lulu Sheng $^{\mathrm{a}}$ \\ Zhijun Xiec Chengping Wenc \\ aDepartment of Intensive Care Unit, First Hospital of Jilin University, Changchun, bepartment of \\ Neurology and Neuroscience Center, First Hospital of Jilin University, Changchun, 'Department of \\ Neurology, Beijing Rehabilitation Hospital affiliated to Capital Medical University, Beijing, China
}

\section{Key Words}

Cerebrovascular Stroke • Serum • Uric acid • Biomarker • Association

\begin{abstract}
Background/Aims: We sought to assess a consecutive number of patients with first-ever acute ischemic stroke (AIS), the clinical relevance in regard to functional outcome of the serum uric acid (SUA) measured at admission. Methods: In 2 prospective centers for observational study, serum concentrations of SUA were measured on admission in the serum of 710 consecutive patients with AIS. SUA concentrations were determined by high-performance liquid chromatography. SUA, NIH stroke scale (NIHSS), and conventional risk factors were evaluated to determine their value to predict functional outcome within 3 months. Results: During the follow-up, an unfavorable functional outcome (defined as a mRS score $>2$ ) was found in 219 (30.8\%) patients. The unfavorable functional outcome distribution across the SUA quartiles ranged between $12.4 \%$ (third quartile) and $50.6 \%$ (first quartile). After adjusting for all other significant outcome predictors, SUA concentration remained an independent unfavorable outcome predictor with an adjusted OR of 0.996 (95\% CI, 0.993-0.998; P<0.001). Conclusions: The data show that the U-shaped nature of the exposure-risk relationship was more prominent when the data were assessed in deciles (based on the SUA values). This model predicted the lowest relative risk of unfavorable outcome in the 67th percentile (corresponding to $309 \mu \mathrm{mol} / \mathrm{L}$ ). SUA was significantly associated with the risk of poor functional outcomes in Chinese patients with stroke.

\section{Introduction}

Stroke is a more common and frequently occurring disease in middle and old aged people in China. The age-standardized incidence and mortality rates were 1114.8 per 100 , 000 people, 246.8 and 114.8 per 100,000 person-years, respectively [1]. Stroke has been 
divided into two major types, hemorrhagic and ischemic. Ischemic stroke (IS) is the most common type of stroke, accounting for $60 \%$ to $80 \%$ of all strokes. IS has a poor prognosis and is associated with high mortality rate. Accurate and prompt prediction of functional outcome in stroke patients is essential for clinicians.

Uric acid (UA) is an end-product of the metabolism of purines and a potent antioxidant compound [2]. Previous studies have reported a relationship between the UA concentration and the risk of diabetes mellitus [3], hypertension [4], metabolic syndrome [5], coronary or cerebrovascular ischemic events [6], atrial fibrillation [7], and stroke [8]. The Framingham cohort found a greater risk for developing cardiovascular disease (CVD) in male subjects with gout [9]. UA as a marker of several metabolic disturbances has been used in clinical practice [10]. A study suggested that circulating UA is a major antioxidant and might help protect against free-radical oxidative damage [11]. The allantoin/UA (AL/UA) ratio is considered to be a marker of the oxidative stress burden in patients with various conditions [12,13].

Oxidative stress has emerged as a key deleterious factor in brain ischemia and reperfusion. Oxidative stress contributes directly to necrosis and apoptosis through a number of pathways in ischemic tissue [14]. However, there were conflicting results about the association between the post-stroke SUA level and the prognosis of stroke in the literature [15-18]. In patients with acute ischemic stroke, Chamorro et al [16]. suggested that there is a $12 \%$ increase in the odds of good clinical outcome for each milligram per deciliter increase of SUA. Similarly, a meta-analysis supported that serum uric acid level had a protective effect on neurological outcome after acute ischemic stroke [17]. However, another study found that a low SUA concentration was modestly associated with a very good short-term outcome [18]. We propose a hypothesis that the concentration of SUA, as a marker of antioxidant, could be a protective predictor for stroke functional outcome. The aim of this prospective cohort study was to verify this hypothesis in Chinese patients with IS.

\section{Materials and Methods}

\section{Patient Population}

This prospective, multicenter cohort study was conducted at 2 Stroke Centers from 2 cities (Changchun and Beijing) in China. The number of AIS patients attended during the study period (From January 2015 through June 2016) determined the sample size.

Patients were eligible for inclusion if they were admitted to the emergency department with a firstever AIS defined according to the World Health Organization ICD-9 criteria and with symptom onset within 24 hours. We excluded patients with missing informed consent, malignant tumor, epileptic seizures, recent surgery or trauma during the preceding 3 months, renal insufficiency (creatinine $>1.5 \mathrm{mg} / \mathrm{dl}$ ), systemic infections at study enrollment, autoimmune diseases, recent intake of allopurinol or lithium, as well as those with a history of history of gouty arthritis or nephropathy. The study was approved by the ethics committee of the First Hospital of Jilin University according to the Helsinki Declaration of 1975. The patients or their relatives gave written informed consent prior to entering the study.

\section{Clinical Variables and Neuroimaging}

At baseline, the following demographical and clinical data were taken: gender, age, BMI (Body Mass Index) and history of conventional vascular risk factors (hypertension, diabetes mellitus, atrial fibrillation, hyperlipoproteinemia and smoking habit) were obtained. Pre-stroke therapy (oral anticoagulants, antiplatelet agents and antihypertensive treatment) and acute treatment (IV thrombolysis and/or mechanical thrombectomy) was recorded. All patients received treatment according to current guidelines. Stroke severity was assessed on admission using the National Institutes of Health Stroke Scale (NIHSS) by a neurologist [19]. Ischemic stroke subtype was classified by a consensus of 2 neurologists, with a third neurologist adjudicating if needed, based on the TOAST (Trial of Org 10172 in Acute Stroke Treatment) criteria [20]. The clinical stroke syndrome was determined by applying the criteria of the Oxfordshire Community Stroke Project: total anterior circulation syndrome (TACS); partial anterior circulation syndrome (PACS); lacunar syndrome (LACS); and posterior circulation syndrome (POCS) [21]. Brain imaging (either 


\section{Cellular Physiology Cell Physiol Biochem 2018;47:2369-2379 \begin{tabular}{ll|l} 
and Biochemistry Published onlIne: July 09, 2018 & $\begin{array}{l}\text { (c) } 2018 \text { The Author(s). Published by S. Karger AG, Basel } \\
\text { www.karger.com/cpb }\end{array}$ \\
\hline
\end{tabular}}

Yang et al.: The Prognostic Value of SUA in Stroke

CT or MRI) was performed routinely within 24 hours after admission. If MRI was performed, DWI lesion volumes were determined by one experienced neurologist unaware of the clinical and laboratory results. The infarct volume was calculated by using the formula $0.5 \times \mathrm{a} \times \mathrm{b} \times \mathrm{c}$ (where a is the maximal longitudinal diameter, $\mathrm{b}$ is the maximal transverse diameter perpendicular to $\mathrm{a}$ and $\mathrm{c}$ is the number of 10 -mm slices containing infarct) [22].

\section{End Points and follow-up}

The primary end-point was functional outcome on month 3. Structured follow-up telephone interview was used, if the patients discharged. The follow-up was conducted base on a standardized interview protocol. The interviewers were centrally trained with the interview protocol. Functional outcome was assessed by the modified Rankin Scale (mRS) [23] blinded to serum biomarkers. A favorable functional outcome was defined as a mRS of 0-2 points, whereas an unfavorable outcome was defined as a mRS of $>2$ points [24]. Secondary end-points were all-cause mortality within 3 months.

\section{Plasma Samples Test}

For all patients, blood was drawn in the emergency room at 6:00 in the first day morning and within 48 hours of symptom onset (within 0-6 [n=175], 6-12 [n=196], 12-24 [n=195], and 24-48 [n=144] hours from symptom onset). After centrifugation for 20 minutes at 3, 000g at room temperature, plasma (from EDTA tube) was aliquoted. SUA concentrations were determined by high-performance liquid chromatography [25]. Diluted samples were filtered through a centrifugal molecular weight cut-off spin filter device (Nanosep, 10kDa MWCO). The deproteinized filtrate was directly injected into an Agilent Series 1100 analytical HPLC system connected to a $250 \mathrm{~mm}$ Zorbax SB-C8 (5 $\mu \mathrm{mol}$ ) analytical column. The mobile phase was $2 \mathrm{mmol} / \mathrm{l}$ NH4H2PO4 at pH 2.95 (isocratic, 1ml/min flow). Each sample was injected two times and the peak area averaged. The total coefficient of variation was $2.8 \%$ at $150 \mu \mathrm{mol} / \mathrm{l}$ and $1.2 \%$ at $600 \mu \mathrm{mol} / \mathrm{l}$. The reliability coefficient for blind replicate measurements was 0.99. The median levels of SUA in 100 age and sex matched healthy individuals was $272 \mu \mathrm{mol} / \mathrm{l}$ and the interquartile ranges (IQRs) was from $190 \mu \mathrm{mol} / \mathrm{l}$ to $358 \mu \mathrm{mol} / \mathrm{l}$. Other biomarkers, such as Fasting blood glucose (FBG), C-reactive protein (CRP), creatinine(Cr), and homocysteine (HCY) were also tested by standard laboratory method. For all measurements, levels that were not detectable were considered to have a value equal to the lower limit of detection of the assay.

\section{Statistical Analysis}

Results are expressed as percentages for categorical variables and as medians (IQRs) for the continuous variables. The distribution of raw biomarker data was skewed. Comparisons for categorical baseline measurements were performed by Fisher exact test and for continuous, not normally distributed baseline data, by the Mann-Whitney U test.

To investigate whether SUA allows predicting of unfavorable functional outcomes, different statistical methods were used. In this study, we included a range of variables as potential confounds in the analyses. These include sex, age, BMI, time from onset to blood collection, prior or acute treatment, stroke subtype, stroke syndrome, vascular risk factors, NIHSS score and serum levels of Hs-CRP, Cr, HCY and FBG. For multivariate analysis, we included SUA and other significant predictors as assessed in univariate analysis. We used crude models and multivariate models adjusted for all significant outcome predictors in univariate analysis and report odds ratios (ORs). For a more detailed exploration of the SUA and outcome relationship, we also used multivariate analysis models to estimate adjusted OR and 95\% CIs of outcome for SUA quartiles (with third SUA quartile as reference).

To examine SUA as a continuous variable, we also used second-degree fractional polynomials to explore the relationship between the variables of interest. If the exposure-risk relationship was nonlinear, we planned further analyses to explore the nature of the relationship using more fine-grain deciles and individually assessing the list of variables previously included as covariates for interaction effects with SUA. All statistical analysis was performed with SPSS for Windows, version 20.0 (SPSS Inc., Chicago, IL, USA) and STATA 9.2 (Stata Corp, College Station, TX), R version 2.8.1. Statistical significance was defined as $\mathrm{P}<0.05$.

\section{Results}

Descriptive Characteristics of Stroke Patients

Of a total of 844 eligible patients, blood samples were collected within day 1 after admission in 752 patients; these samples could not be performed in 92 patients (14 patients 
died before the samples collection, 45 were discharged to another institution, 24 refused to included, and blood sampling was lost in 9 patients). Of the original 752 stroke patients, 710 completed the 3-month follow-up and were available for analysis (30 lost follow-up and 12 withdrawals). However, these included patients were similar in terms of baseline characteristics (age $[\mathrm{P}=0.55]$, sex $[\mathrm{P}=0.71]$, NIHSS $[\mathrm{P}=0.28]$, and $\mathrm{BMI}[\mathrm{P}=0.41]$ ) compared with the overall cohort. Overall median age was 59 years (IQR, 51-69 years), and $52.8 \%$ were men. At admission, the median NIHSS score was 7 (IQR, 4-12), and the median SUA concentration was $255 \mu \mathrm{mol} / \mathrm{L}$ (IQR, 175-342 $\mu \mathrm{mol} / \mathrm{L}$ ). The median SUA in stroke patients was significantly lower than in controls (272 [IQR, 190-358] $\mu \mathrm{mol} / \mathrm{L} ; P=0.009$ ). The baseline characteristics of the patients presenting with acute ischemic stroke are described in Table 1.

\section{Main Results}

Stroke treatment was conservative in 642 (90.4\%) patients, and 201 (28.3\%) patients underwent thrombolysis. During the 3-month follow-up period, an unfavorable functional outcome (defined as a mRS score $>2$ ) was found in 219 patients (30.8\%; 95\% CI, 27.4\%-34.2\%). Eightyfour patients died, and the mortality rate was thus $11.8 \%$ (95\% CI, 9.5\%-14.2\%). Daily blood samples were obtained for 7 days after admission in a subgroup of 55 patients (26 women; median age [IQR], 58 [50-68] years), 18 of whom subsequently experienced unfavorable functional outcomes. The result illustrates the time course of SUA concentration, showing significant changes with day of sampling $(\mathrm{P}<0.001)$, with lowest levels on day 1 $(\mathrm{P}<0.001$, compared with days 0 , and $2-7$, respectively), increasing to a plateau by days 3 to 7 .

SUA concentration was higher in men (median, $298 \mu \mathrm{mol} / \mathrm{L}$ compared with 219 $\mu \mathrm{mol} / \mathrm{L}$ in women), and among those with ischemic heart disease and hypertension $(\mathrm{P}<0.05)$. The differences in SUA in those with diabetes were not significant $(\mathrm{P}=0.322)$. A significant relationship was observed between serum $\mathrm{Cr}$ and SUA $(\mathrm{r}=0.246, \mathrm{P}<0.001)$. SUA was also inversely correlated with FBG $(\mathrm{r}=-0.242 ; \mathrm{P}<0.001)$ and the infarct volume $(\mathrm{N}=448 ; \mathrm{r}=-0.183$; $\mathrm{P}=0.003$ ). At admission, in patients with a minor stroke (NIHSS score $<5$ ), the median SUA concentration was higher than that observed in patients with moderate-to-high clinical severity $(287 \mu \mathrm{mol} / \mathrm{L}$ [IQR, 201$392 \mu \mathrm{mol} / \mathrm{L}]$ vs $222 \mu \mathrm{mol} / \mathrm{L}$ (IQR, 159$303 \mu \mathrm{mol} / \mathrm{L}$ ); $\mathrm{P}<0.001)$. Nonparametric Spearman rank correlation revealed a statistically significant negative correlation
Table 1. Baseline Characteristics of Stroke Patients. IQR, interquartile range; BMI, body mass index; NIHSS, National Institutes of Health Stroke Scale; HsCRP, High-sensitivity-C-reactive protein; TACS, total anterior circulation syndrome; PACS, partial anterior circulation syndrome; LACS, lacunar syndrome; POCS, posterior circulation syndrome; SUA, serum uric acid; FBG, Fasting Blood Glucose. ${ }^{+}$The results presented as n (\%) or median(IQRs)

\begin{tabular}{|c|c|}
\hline Baseline Characteristics $^{\dagger}$ & ALL $(N=710)$ \\
\hline Age, median (IQR), y & $59(51-69)$ \\
\hline Male gender, n (\%) & $375(52.8)$ \\
\hline BMI, median (IQR), kg/m2 & $26.0(24.5-28.6)$ \\
\hline \multicolumn{2}{|l|}{ Vascular risk factors, $\mathrm{n}(\%)$} \\
\hline Hypertension & $445(62.7)$ \\
\hline Diabetes mellitus & $178(25.1)$ \\
\hline Coronary artery disease & $155(21.8)$ \\
\hline Congestive heart failure & $142(20.0)$ \\
\hline Hypercholesterolemia & $159(22.4)$ \\
\hline Atrial fibrillation & 113(15.9) \\
\hline Current smoking & $165(13.2)$ \\
\hline History of cerebrovascular event & 133(18.7) \\
\hline NIHSS score at admission, median (IQR) & $7(4-12)$ \\
\hline DWI lesion size( $N=448)$, median (IQR), $\mathrm{ml}$ & $28(11-47)$ \\
\hline Time to blood collection from onset, median (IQR), h & $12.0(5.5-21.5)$ \\
\hline \multicolumn{2}{|l|}{ Stroke syndrome, n (\%) } \\
\hline TACS & $159(22.4)$ \\
\hline PACS & $243(34.2)$ \\
\hline LACS & $165(23.2)$ \\
\hline POCS & $143(20.1)$ \\
\hline \multicolumn{2}{|l|}{ TOAST subtype, $\mathrm{n}(\%)$} \\
\hline Large-vessel disease & $178(25.1)$ \\
\hline Small-artery disease & $149(21.0)$ \\
\hline Cardioembolic & $155(21.8)$ \\
\hline Multiple causes & $105(14.8)$ \\
\hline Undetermined & $123(17.3)$ \\
\hline \multicolumn{2}{|l|}{ Laboratory findings, median (IQR) } \\
\hline $\mathrm{FBG}, \mathrm{mmol} / \mathrm{l}$ & $6.37(5.62-6.93)$ \\
\hline Creatinine, mmol/l & $88.4(71.5-103.2)$ \\
\hline Hs-CRP, mg/l & $0.44(0.21-1.15)$ \\
\hline SUA, $\mu \mathrm{mol} / \mathrm{l}$ & $255(175-342)$ \\
\hline \multicolumn{2}{|l|}{ Therapies before admission, $\mathrm{n}(\%)$} \\
\hline Anti-platelet agents & $233(32.8)$ \\
\hline Anti-coagulation & $176(24.8)$ \\
\hline \multicolumn{2}{|l|}{ Acute treatment, $\mathrm{n}(\%)$} \\
\hline IV thrombolysis & $201(28.3)$ \\
\hline Mechanical thrombectomy & $82(11.5)$ \\
\hline IV thrombolysis and/or mechanical thrombectomy & $248(34.9)$ \\
\hline
\end{tabular}




\section{Cellular Physiology Cell Physiol Biochem 2018;47:2369-2379 \begin{tabular}{ll|l} 
DOI: 10.1159/000491609 & $\begin{array}{l}\text { O 2018 The Author(s). Published by S. Karger AG, Basel } \\
\text { www.karger.com/cpb }\end{array}$
\end{tabular} Yang et al.: The Prognostic Value of SUA in Stroke}

Fig. 1. The incidence for unfavorable functional outcome $(95 \% \mathrm{CI})$ according to the baseline concentration of SUA quartiles. The unfavorable outcome distribution across the SUA quartiles ranged between $12.4 \%$ (third quartile) to $50.6 \%$ (first quartile), $\mathrm{P}$ for trend $<0.001$. The red symbol represents incidence for unfavorable functional outcome; The blue and green symbols represent $95 \% \mathrm{CI}$ of incidence: low and high. SUA=Serum uric acid.

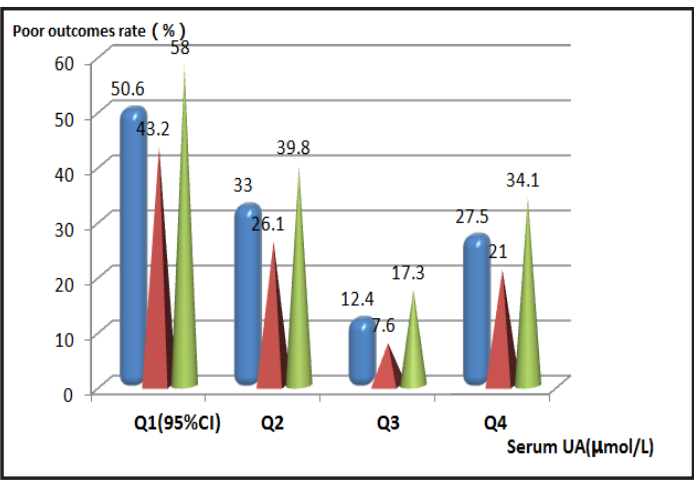

Fig. 2. The incidence for unfavorable functional outcome according to the baseline concentration of SUA deciles. This model predicted the lowest risk of unfavorable outcome in the 60 70percentile (corresponding to $286 \sim 324 \mu \mathrm{mol} / \mathrm{l}$ of SUA) with $7.0 \%$ of unfavorable outcome. SUA=Serum uric acid.

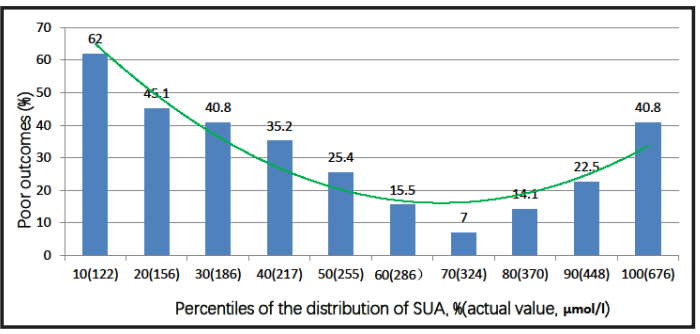

between SUA concentration and NIHSS score $(r=-0.216 ; P<0.001)$. We also examined the relationship between SUA concentration and stroke subtypes. The median SUA concentration was significantly lower for atherosclerosis than that for the other stroke subtype groups (223 [IQR, $162320 \mu \mathrm{mol} / \mathrm{L}]$ vs. $276 \mu \mathrm{mol} / \mathrm{L}$ [IQR, 195-367 $\mu \mathrm{mol} / \mathrm{L}]$, respectively; $P=0.002$ ).

\section{SUA and functional outcome after 3 months}

SUA concentration in patients with an unfavorable outcomes were significantly lower than those patients with favorable outcomes $(192 \mu \mathrm{mol} / \mathrm{L}$ [IQR, 138-235 $\mu \mathrm{mol} / \mathrm{L}]$ vs. 275 $\mu \mathrm{mol} / \mathrm{L}[\mathrm{IQR}, 195-344 \mu \mathrm{mol} / \mathrm{L}] ; \mathrm{P}<0.001)$. The unfavorable functional outcome distribution across the SUA quartiles ranged between $12.4 \%$ (third quartile) and 50.6\% (first quartile), $\mathrm{P}$ for trend $<0.001$ (Fig. 1). Interestingly, Fig. 2 shows that the nature of the SUA functional outcome relationship was more prominent when the data were assessed in deciles (based on the SUA values). This model predicted the lowest relative risk of unfavorable outcome in the 60th to 70th percentile (corresponding to $286-324 \mu \mathrm{mol} / \mathrm{L}$ of SUA) with $7.0 \%$ of unfavorable outcome.

In univariate logistic regression analysis, we calculated the ORs of SUA concentration as compared with the NIHSS score and other risk factors as presented in Table 2. With an unadjusted OR of 0.992 (95\% CI, 0.988-0.995; P<0.001), SUA concentration had a strong association with unfavorable functional outcome. After adjusting for all other significant outcome predictors in univariate logistic regression analysis, SUA concentration remained an independent unfavorable outcome predictor with an adjusted OR of 0.996 (95\% CI, 0.993-0.998; $\mathrm{P}<0.001$ ). In addition, age, BMI, the NIHSS score, FBG, and Hs-CRP remained as significant outcome predictors, unlike all others assessed. For a more detailed exploration of the SUA concentration-functional outcome relationship, we also used multivariate analysis models to estimate adjusted OR and 95\% CIs of unfavorable functional outcome for SUA quartiles (with third quartile of SUA as reference). In multivariate models comparing the first, second, and fourth quartiles against the third quartile of the SUA (Table 3), levels of SUA were associated with unfavorable functional outcome. The independent association of SUA with unfavorable functional outcome was confirmed using the likelihood ratio test $(\mathrm{P}=0.005)$.

Again, Fig. 3 shows that the U-shaped nature of the exposure-risk relationship was more prominent when the data were assessed in deciles (based on the SUA values). Patients in the 60th to 70th percentile of the distribution were chosen as the reference 
category for the categorical analyses. In multivariate logistic regression analysis adjusting for sex, age, BMI, time from onset to blood collection, prior or acute treatment, stroke subtype, stroke syndrome, vascular risk factors, NIHSS score, and serum levels of Hs-CRP, Cr, HCY, and FBG, SUA concentration remained an independent unfavorable outcome predictor (Fig 3). The line shows the best-fit analysis for the continuous data (a second-degree fractional polynomial with orders 3 and 3). This polynomial had a significantly better fit compared with both a straight line $(\mathrm{P}=0.021)$ and the null model $(\mathrm{P}=0.003)$. This model predicted the lowest relative risk of unfavorable outcome in the 67th percentile (corresponding to 309 $\mu \mathrm{mol} / \mathrm{L}$ of SUA).

The

relationship between levels of SUA and functional outcome was also assessed between sexes. In
Table 2. Univariate and multivariate logistic regression analysis for unfavorable functional outcome. ${ }^{*}$ Note that the odds ratio corresponds to a unit increase in the explanatory variable. "In the subgroup of patients $(\mathrm{N}=448)$ in whom MRI evaluations were performed. OR, odds ratio; CI, confidence interval; Hs-CRP, High-sensitivity-C-reactive protein; NIHSS, National Institutes of Health Stroke Scale; TACS, total anterior circulation syndrome; SUA, serum uric acid; FBG, Fasting Blood Glucose

\begin{tabular}{lcccccc}
\hline \multicolumn{1}{c}{ Parameter } & \multicolumn{3}{c}{ Univariate Analysis $^{-}$} & \multicolumn{3}{c}{ Multivariate Analysis } \\
& $\mathrm{OR}^{+}$ & $95 \% \mathrm{CI}^{+}$ & $\mathrm{P}$ & $\mathrm{OR}^{+}$ & $95 \% \mathrm{CI}^{+}$ & $\mathrm{P}$ \\
\hline Age (increase per unit) & 1.12 & $1.04-1.22$ & $<0.001$ & 1.08 & $1.02-1.17$ & 0.003 \\
NIHSS score (increase per unit) & 1.28 & $1.15-1.39$ & $<0.001$ & 1.20 & $1.12-1.29$ & $<0.001$ \\
Lesion volumes\# (increase per unit) & 1.22 & $1.09-1.38$ & 0.006 & 1.10 & $1.03-1.24$ & 0.012 \\
Atrial fibrillation (Yes vs. no) & 1.75 & $1.22-3.02$ & 0.025 & 1.50 & $0.95-3.12$ & 0.232 \\
Smoking history (Yes vs. no) & 1.33 & $1.06-2.01$ & 0.042 & 1.24 & $0.92-2.12$ & 0.283 \\
Hypertension (Yes vs. no) & 1.60 & $1.03-2.45$ & 0.048 & 1.48 & $0.90-2.69$ & 0.424 \\
Stroke syndrome (TACS VS. other) & 3.12 & $1.76-4.87$ & 0.009 & 1.50 & $0.76-3.66$ & 0.511 \\
Stroke etiology (Small-vessel occlusive vs. other) & 0.69 & $0.54-0.86$ & 0.033 & 0.76 & $0.60-1.08$ & 0.079 \\
Hs-CRP (increase per unit) & 1.21 & $1.09-1.42$ & 0.004 & 1.09 & $1.03-1.35$ & 0.006 \\
FBG (increase per unit) & 1.15 & $1.07-1.30$ & 0.022 & 1.06 & $1.02-1.25$ & 0.039 \\
HCY (increase per unit) & 1.10 & $1.04-1.19$ & 0.009 & 1.08 & $1.01-1.20$ & 0.012 \\
SUA (increase per unit) & 0.992 & $0.988-0.995$ & $<0.001$ & 0.996 & $0.993-0.998$ & $<0.001$ \\
\hline
\end{tabular}

Table 3. Multivariate logistic regression analysis models to estimate adjusted OR and 95\% CIs of stroke unfavorable functional outcome for SUA quartiles ${ }^{\ddagger \ddagger}$ adjust for sex, age, BMI, time from onset to blood collection, prior or acute treatment, stroke subtype, stroke syndrome, vascular risk factors, NIHSS score and serum levels of Hs-CRP, Cr, HCY and FBG. \# SUA levels in Quartile 1 ( $<175 \mu \mathrm{mol} / \mathrm{l})$, Quartile 2 (175-255 $\mu \mathrm{mol} / \mathrm{l})$,

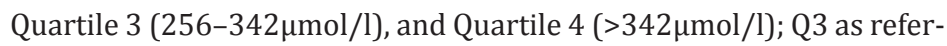
ence with $\mathrm{OR}=1$. OR, odds ratio; $\mathrm{CI}$, confidence interval; Hs-CRP: highsensitivity C-reactive protein; FBG: fasting blood glucose; BMI, body mass index; NIHSS, National Institutes of Health Stroke Scale; SUA, serum uric acid

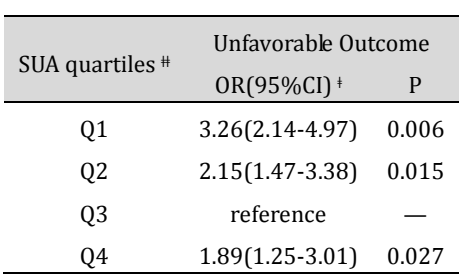

Fig. 3. Odds ratio (OR) of unfavorable functional outcome according to the concentration of SUA, measured by the percentile of the distribution of SUA among the stroke patients. The upper and down points indicate $95 \%$ confidence intervals (CI). Patients in the 60th to 70th percentile of the distribution were chosen as the reference category for the categorical analyses. In multivariate logistic regression analysis, the adjusted factors including sex, age, BMI, time from onset to blood collection, prior or acute treatment, stroke subtype, stroke syndrome, vascular risk factors, NIHSS score and serum levels of HsCRP, Cr, HCY and FBG. OR=odds ratio; $\mathrm{CI}=$ confidence

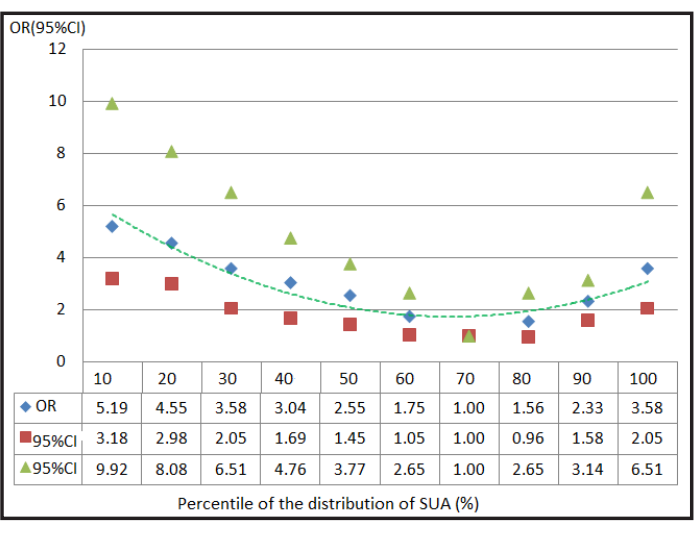
interval; Hs-CRP=High-sensitivity-C-reactive protein; NIHSS=National Institutes of Health Stroke Scale; SUA=serum uric acid; FBG= Fasting Blood Glucose. 


\section{Cellular Physiology Cell Physiol Biochem 2018;47:2369-2379 \\ \begin{tabular}{ll|l} 
and Biochemistry Published onlıne: July 09, 2018 & $\begin{array}{l}\text { (c) } 2018 \text { The Author(s). Published by S. Karger AG, Basel } \\
\text { www.karger.com/cpb }\end{array}$ \\
\hline
\end{tabular} \\ Yang et al.: The Prognostic Value of SUA in Stroke}

univariate logistic regression analysis, for each increase per unit of SUA, the adjusted risks of unfavorable outcome were determined as 0.997 (95\% CI, 0.994-0.999; $\mathrm{P}=0.003$ ) and 0.995 (95\% CI, 0.992-0.998; $\mathrm{P}<0.001)$ for men and women, respectively-thus, indicating that SUA is an independent unfavorable outcome predictor. The AUROCs for SUA to diagnose unfavorable outcome in men and women were 0.703 (95\% CI, 0.644-0.775; $\mathrm{P}<0.001)$ and 0.724 (95\% CI, 0.668-0.786; $\mathrm{P}<0.001$ ), respectively.

\section{Discussion}

The relationship between UA and stroke prognosis is ambiguous. Contrasting observations have been made between SUA and ischemic stroke outcomes in studies involving Caucasian populations [15-18]. In this study, we found that SUA was significantly associated with the risk of unfavorable functional outcome, and the nature of this relationship was nonlinear (U-shaped). Depending on its concentration, SUA may exhibit protective and deleterious effects on 3 months of stroke outcomes in Chinese population, in agreement with a previous report [25], which found that more patients with low $(<280 \mu \mathrm{M})$ and high $(>410 \mu \mathrm{M})$ UA levels had poor functional outcomes (36\% and $27 \%$, respectively) compared with those with UA levels between 340 and $410 \mu \mathrm{M}(14 \%)$. In this study, we confirmed that stroke patients with the SUA concentration in 286 to $324 \mu \mathrm{mol} / \mathrm{L}$ had the best functional outcome (7\%). In addition, The URICO-ICTUS trial showed that uric acid therapy improved clinical outcome in women than in men [26]. In this study, we also found that the predictive value of SUA was better in women than in men.

Previous studies suggested that SUA had protective or deleterious effects on stroke outcomes. Hyperuricemia was an independent risk factor of ischemic stroke [27] and early death in acute stroke [28]. Chiquete et al [18]. confirmed that a low SUA concentration is modestly associated with a very good short-term outcome. However, a meta-analysis supported that serum uric acid level had a protective effect on neurological outcome after acute ischemic stroke [17]. Wu et al [29]. have shown that lower serum uric acid levels independently predicted poor functional outcomes at 1 year after ischemic stroke onset (OR, 0.335; $P=0.003)$, whereas another study reported that low SUA level $(<221 \mu \mathrm{mol} / \mathrm{L})$ independently and strongly predicts the short-term poor functional outcome in acute stroke with normoglycemia other than diabetes or prediabetes [30].

It had also been proven in another study that low SUA was associated with larger infarction area and worse neurological deficit in the stroke patients [31]. In this study, we also found that SUA was also inversely correlated with infarct volume $(\mathrm{P}=0.003)$ and neurological deficit $(\mathrm{P}<0.001)$. Consistent with those data, a study suggested that decreases in UA during the first week after onset of stroke correlates with more severe stroke, unfavorable stroke evolution, and poor long-term stroke outcome [32]. This study also found that UA concentrations decreased significantly during the first 7 days after stroke onset before returning to baseline $(\mathrm{P}<0.001)$. Interestingly, we found that the SUA concentration was with lowest levels on day $1(\mathrm{P}<0.001)$, increasing to a plateau by days 3 to 7 . Similarly, in untreated patients, SUA declined at 6 to 12 hours $(\mathrm{P}=0.298), 48$ hours $(\mathrm{P}=0.010)$, and 90 days $(\mathrm{P}=0.030)$ after stroke onset [26]. When recorded on admission, different variables were associated with poor outcome in stroke patients, for example, HS-CRP [33], HCY [33], glucose [34], and NIHSS score [35]. In this study, we also found that the NIHSS score, FBG, and Hs-CRP remained significant outcome predictors.

This observational study cannot determine the causal relationship between SUA and functional outcomes. We cannot confirm the role of UA treatments on the stroke outcomes. URICO-ICTUS trial suggested that UA therapy may prevent early ischemic worsening (EIW) after acute stroke in thrombolysed patients [36]. In women with acute ischemic stroke treated with alteplase, the administration of UA reduced infarct growth in selected patients and was better than placebo to reach excellent outcome [26]. Another study confirmed that UA improves glucose-driven oxidative stress in human ischemic stroke, and UA therapy 
was associated with reduced infarct growth and improved outcome in patients with hyperglycemia during acute stroke [37]. However, Chamorro et al [38]. suggested that the addition of uric acid to thrombolytic therapy did not increase the proportion of patients who achieved excellent outcome after stroke compared with placebo, but it did not lead to any safety concerns. Further study on the role of UA treatments on the stroke outcomes in China population should be carried out.

The U shape suggests that SUA may exhibit protective and deleterious effects on stroke outcomes. Previous studies suggested that hyperuricemia was a risk factor for the poor outcomes [30] and through the following pathway: (1) insulin resistance [39]; (2) increasing the risk of hypertension and further aggravated atherosclerosis [40]; (3) impair the selfregulation of the arteriole [41]; (4) UA induces cardiomyocyte apoptosis through activation of calpain-1 and endoplasmic reticulum stress [42]. Furthermore, high UA exposure activated the ROS-AMPK pathway, impaired CD68 expression [43], and induced oxidative damage and inhibited the viability of cardiomyocytes by activating ERK/p38 signaling [44]. The neuroprotective function of SUA can be explained from the following aspects. First, UA is the main endogenous antioxidant in human plasma, its multiple effects include scavenging hydroxyl radicals, hydrogen peroxide, and peroxynitrite and prevent lipid peroxidation [45], and these effects mainly take place within the walls of the brain vessels [46]. Second, it has been argued that SUA could be a compensatory mechanism to counteract oxidative damage related to atherosclerosis and aging in humans [47]. Third, the administration of UA allowed a more efficient clearance of peroxynitrite-derived free radicals that limited glucose toxicity and secondary cell death $[37,48]$. Lastly, SUA was one of the most important serum antioxidant factors and an anti-inflammatory factor [49]; it could decrease the degradation of the extracellular superoxide dismutase-3(SOD3) [50]. In addition, in the chronic disease, UA was a reaction of the negative feedback mechanism to counterbalance the increased level of reactive oxygen species (ROS) [51].

The following limitations of our study must be taken into account. The overwhelming majority of our sample was Chinese, limiting the generalizability to other ethnicities. In addition, median age of 59 (IQR: 51-69) years seems too low. This may cause selective bias. Second, it is not yet established whether UA treatment improve the prognosis of stroke, and any causal role of these parameters in stroke pathophysiology is unproven. Third, several medical conditions, including cancer, dementia, or other chronic diseases, are associated with UA levels, and could also be associated with stroke. In addition, it is possible that insufficient nutrient intake in more severe strokes may be the reason for worse outcome in the lowest quartile of SUA. However, in this study, we did not obtain the information about nutrient intake. Interestingly, a previous study suggested that higher levels of meat and seafood consumption are associated with an increased risk of gout [52]. Therefore, we could not eliminate all of those factors. Fourth, there is evidence that UA may favorably influence stroke outcomes through multiple pathways, including hypertension, insulin resistance and secretion, 2 diabetes, and chronic inflammation. The inclusion of those factors in the models could possibly lead to over-adjustment, which tends to attenuate the associations. In addition, there were several drugs having impacts on SUA levels, for example, aspirin and diuretics. However, we did not collect this information and consider those factors as confounding factors. Lastly, this study measured biomarkers in plasma, not in cerebral spinal fluid (CSF). It is still uncertain whether peripheral UA levels reflect similar changes in the central nervous system (CNS). Further study is needed to confirm the correction between UA levels in serum and in CSF.

\section{Conclusion}

SUA was significantly associated with the risk of poor functional outcomes in Chinese patients with stroke, independent of established conventional risk factors. The nature of those relationships was nonlinear (U-shaped). Whether stroke with abnormal UA concentrations 


\section{Cellular Physiology Cell Physiol Biochem 2018;47:2369-2379 \begin{tabular}{l|l|l} 
and Biochemistry 10.1159/000491609 & $\begin{array}{l}\text { ( ) 2018 The Author(s). Published by S. Karger AG, Basel } \\
\text { www.karger.com/cpb }\end{array}$
\end{tabular} \\ Yang et al.: The Prognostic Value of SUA in Stroke}

should be supplemented or eliminated to maintain their optimal UA concentrations to prevent poor outcomes requiring further long-term controlled clinical trials.

\section{Acknowledgements}

This study was supported by the Supported by the grants from the National Science Foundation of China (No. 31600820) and The Health and Family Planning Commission of Jilin Province (No. 2016Q036). We express our gratitude to all the patients who participated in this study, and thereby made this work possible. All authors have contributed significantly, and that all authors are in agreement with the content of the manuscript.

\section{Disclosure Statement}

The authors declare to have no competing interests. The funding organizations had no role in the design and concept of the study; the collection, management, analysis, and interpretation of the data; or the preparation, review, or approval of the manuscript.

\section{References}

1 Wang W, Jiang B, Sun H, Ru X, Sun D, Wang L, Wang L, Jiang Y, Li Y, Wang Y, Chen Z, Wu S, Zhang Y, Wang D, Wang Y, Feigin VL; NESS-China Investigators: Prevalence, Incidence and Mortality of Stroke in China: Results from a Nationwide Population-Based Survey of 480, 687 Adults. Circulation 2017;135:759-771

$\longrightarrow 2$ Buettner GR: The pecking order of free radicals and antioxidants: lipid peroxidation, -tocopherol, and ascorbate. Arch Biochem Biophys 1993;300:535-543.

-3 Hayden M R, Tyagi S C. Uric acid: A new look at an old risk marker for cardiovascular disease, metabolic syndrome, and type 2 diabetes mellitus: The urate redox shuttle. Nutr Metab (Lond) 2004;1 10.

-4 Sundström J, Sullivan L, D’Agostino RB, Levy D, Kannel WB, Vasan RS: Relations of serum uric acid to longitudinal blood pressure tracking and hypertension incidence. Hypertension 2005;45:28-33.

-5 Ford E S, Li C, Cook S, Choi HK: Serum concentrations of uric acid and the metabolic syndrome among US children and adolescents. Circulation 2007;115:2526-2532.

6 Kanbay M, Segal M, Afsar B, Kang DH, Rodriguez-Iturbe B, Johnson RJ: The role of uric acid in the pathogenesis of human cardiovascular disease. Heart 2013;99:759-766.

7 Zhang CH, Huang DS, Shen D, Zhang LW, Ma YJ, Wang YM, Sun HY: Association Between Serum Uric Acid Levels and Atrial Fibrillation Risk. Cell Physiol Biochem 2016;38:1589-1595.

-8 Hozawa A, Folsom AR, Ibrahim H, Nieto FJ, Rosamond WD, Shahar E: Serum uric acid and risk of ischemic stroke: the ARIC Study. Atherosclerosis 2006;187:401-407.

-9 Abbott RD, Brand FN, Kannel WB, Castelli WP: Gout and coronary heart disease: the Framingham Study. J Clin Epidemiol 1988; 41:237-242.

-10 Tsouli SG, Liberopoulos EN, Mikhailidis DP, Athyros VG, Elisaf MS: Elevated serum uric acid levels in metabolic syndrome: an active component or an innocent bystander? Metabolism 2006;55:1293-1301.

11 Fabbrini E, Serafini M, Baric IC, Hazen SL, Klein S: Effect of plasma uric acid on antioxidant capacity, oxidative stress, and insulin sensitivity in obese subjects. Diabetes 2014;63:976-981.

-12 Kand'ár R, Záková P, Muzáková V: Monitoring of antioxidant properties of uric acid in humans for a consideration measuring of levels of allantoin in plasma by liquid chromatography. Clin Chim Acta 2006;365:249-256.

13 Chung WY, Benzie IF: Plasma allantoin measurement by isocratic liquid chromatography with tandem mass spectrometry: method evaluation and application in oxidative stress biomonitoring. Clin Chim Acta 2013;424:237-244.

14 Manzanero S, Santro T, Arumugam TV: Neuronal oxidative stress in acute ischemic stroke: sources and contribution to cell injury. Neurochem Int 2013;62: 712-718. 


\section{Cellular Physiology Cell Physiol Biochem 2018;47:2369-2379 \begin{tabular}{l|l} 
DOI: 10.1159/000491609 & $\begin{array}{l}\text { O 2018 The Author(s). Published by S. Karger AG, Basel } \\
\text { www.karger.com/cpb }\end{array}$
\end{tabular}}

Yang et al.: The Prognostic Value of SUA in Stroke

15 Cherubini A, Polidori MC, Bregnocchi M, Pezzuto S, Cecchetti R, Ingegni T, di Iorio A, Senin U, Mecocci P: Antioxidant profile and early outcome in stroke patients. Stroke 2000;31:2295-2300.

16 Chamorro A, Obach V, Cervera A, Revilla M, Deulofeu R, Aponte JH: Prognostic significance of uric acid serum concentration in patients with acute ischemic stroke. Stroke 2002;33:1048-1052.

17 Wang Z, Lin Y, Liu Y, Chen Y, Wang B, Li C, Yan S, Wang Y, Zhao W: Serum uric acid levels and outcomes after acute ischemic stroke. Mol Neurobiol 2016;53:1753-1759.

-18 Chiquete E, Ruiz-Sandoval JL, Murillo-Bonilla LM, Arauz A, Orozco-Valera DR, Ochoa-Guzmán A, VillarrealCareaga J, León-Jiménez C, Barinagarrementeria F, Ramos-Moreno A, Cantú-Brito C: Serum uric acid and outcome after acute ischemic stroke: PREMIER study. Cerebrovascular Diseases 2013;35:168-174.

19 Brott T, Adams HP Jr, Olinger CP, Marler JR, Barsan WG, Biller J, Spilker J, Holleran R, Eberle R, Hertzberg V: Measurements of acute cerebral infarction: A clinical examination scale. Stroke 1989;20:864-870.

20 Adams HP Jr, Bendixen BH, Kappelle LJ, Biller J, Love BB, Gordon DL, Marsh EE $3^{\text {rd }}$ : Classification of subtype of acute ischemic stroke. Definitions for use in a multicenter clinical trial. TOAST. Trial of Org 10172 in Acute Stroke Treatment. Stroke 1993;24:35-41.

21 Bamford J, Sandercock P, Dennis M, Burn J, Warlow C: Classification and natural history of clinically identifiable subtypes of cerebral infarction. Lancet 1991;337:1521-1526.

22 Sims, JR, Gharai LR, Schaefer PW, Vangel M, Rosenthal ES, Lev MH, Schwamm LH: ABC/2 for rapid clinical estimate of infarct, perfusion, and mismatch volumes. Neurology 2009;72:2104-2110.

23 Bonita BR: Modification of Rankin Scale: recovery of motor function after stroke. Stroke 1988;19:14971500.

24 Qi A, Li Y, Liu Q Si JZ, Tang XM, Zhang ZQ, Qi QD, Chen WB: Thioredoxin is a novel diagnostic and prognostic marker in patients with ischemic stroke. Free Radic Biol Med 2015;80:129-135.

25 Seet R CS, Kasiman K, Gruber J, Tang SY, Wong MC, Chang HM, Chan YH, Halliwell B, Chen CP: Is uric acid protective or deleterious in acute ischemic stroke? A prospective cohort study. Atherosclerosis 2010;209:215-219.

-26 Llull L, Laredo C, Renú A, Pérez B, Vila E, Obach V, Urra X, Planas A, Amaro S, Chamorro Á: Uric acid therapy improves clinical outcome in women with acute ischemic stroke. Stroke 2015;46:2162-2167.

-27 Chen JH, Chuang SY, Chen HJ, Yeh WT, Pan WH: Serum uric acid level as an independent risk factor for all-cause, cardiovascular, and ischemic stroke mortality: A Chinese cohort study. Arthritis Rheum 2009;61:225-232.

28 Karagiannis A, Mikhailidis DP, Tziomalos K, Sileli M, Savvatianos S, Kakafika A, Gossios T, Krikis N, Moschou I, Xochellis M, Athyros VG: Serum uric acid as an independent predictor of early death after acute stroke. Circ J 2007;71:1120-1127.

29 Wu H, Jia Q, Liu G, Liu L, Pu Y, Zhao X, Wang C, Wang Y, Wang Y: Decreased uric acid levels correlate with poor outcomes in acute ischemic stroke patients, but not in cerebral hemorrhage patients. J Stroke Cerebrovasc Dis 2014;23:469-475.

30 Wu S, Pan Y, Zhang N, Jun WY, Wang C; Investigators for the Survey on Abnormal Glucose Regulation in Patients With Acute Stroke Across China (ACROSS-China): Lower serum uric acid level strongly predict short-term poor functional outcome in acute stroke with normoglycaemia: a cohort study in China. BMC Neurology 2017;17: 21.

-31 Leinonen JS, Ahonen JP, Lönnrot K, Jehkonen M, Dastidar P, Molnár G, Alho H: Low plasma antioxidant activity is associated with high lesion volume and neurological impairment in stroke. Stroke 2000;31:3339.

-32 Brouns R, Wauters A, Van De Vijver G, De Surgeloose D, Sheorajpanday R, De Deyn PP: Decrease in uric acid in acute ischemic stroke correlates with stroke severity, evolution and outcome. Clin Chem Lab Med 2010;48:383-390.

33 Tu WJ, Zhao SJ, Liu TG, Yang DG, Chen H: Combination of high-sensitivity C-reactive protein and homocysteine predicts the short-term outcomes of Chinese patients with acute ischemic stroke. Neurol Res 2013;35:912-921.

34 Cao W, Ling Y, Wu F, Yang L, Cheng X, Dong Q: Higher fasting glucose next day after intravenous thrombolysis is independently associated with poor outcome in acute ischemic stroke. J Stroke Cerebrovasc Dis 2015;24:100-103.

-35 Tu WJ, Zhao SJ, Xu DJ, Chen H: Serum 25-hydroxyvitamin D predicts the short-term outcomes of Chinese patients with acute ischaemic stroke. Clin Sci (Lond) 2014;126:339-346. 


\section{Cellular Physiology Cell Physiol Biochem 2018;47:2369-2379 \begin{tabular}{l|l} 
DOI: 10.1159/000491609 & $\begin{array}{l}\text { O 2018 The Author(s). Published by S. Karger AG, Basel } \\
\text { www.karger.com/cpb }\end{array}$
\end{tabular}}

Yang et al.: The Prognostic Value of SUA in Stroke

-36 Amaro S, Laredo C, Renú A, Llull L, Rudilosso S, Obach V, Urra X, Planas AM, Chamorro Á; URICO-ICTUS Investigators: Uric Acid Therapy Prevents Early Ischemic Stroke Progression. Stroke 2016;47:2874-2876.

-37 Amaro S, Llull L, Renú A, Laredo C, Perez B, Vila E, Torres F, Planas AM, Chamorro Á: Uric acid improves glucose-driven oxidative stress in human ischemic stroke. Ann Neurol 2015;77:775-783.

-38 Chamorro Á, Amaro S, Castellanos M, Segura T, Arenillas J, Martí-Fábregas J, Gállego J, Krupinski J, Gomis M, Cánovas D, Carné X, Deulofeu R, Román LS, Oleaga L, Torres F, Planas AM; URICO-ICTUS Investigators: Safety and efficacy of uric acid in patients with acute stroke (URICO-ICTUS): a randomised, double-blind phase 2b/3 trial. Lancet Neurol 2014;13:453-460.

-39 Klein BE, Klein R, Lee KE: Components of the metabolic syndrome and risk of cardiovascular disease and diabetes in Beaver Dam. Diabetes Care 2002;25:1790-1794.

40 Rich MW. Uric acid: is it a risk factor for cardiovascular disease? Am J Cardiol 2000;85:1018-1021.

-41 Johnson RJ, Kang DH, Feig D, Kivlighn S, Kanellis J, Watanabe S, Tuttle KR, Rodriguez-Iturbe B, HerreraAcosta J, Mazzali M: Is there a pathogenetic role for uric acid in hypertension and cardiovascular and renal disease? Hypertension 2003;41:1183-1190.

42 Yan M, Chen K, He L, Li S, Huang D, Li J: Uric Acid Induces Cardiomyocyte Apoptosis via Activation of Calpain-1 and Endoplasmic Reticulum Stress. Cell Physiol Biochem 2018;45:2122-2135.

43 Luo C, Lian X, Hong L, Zou J, Li Z, Zhu Y, Huang T, Zhang Y, Hu Y, Yuan H, Wen T, Zhuang W, Cai B, Zhang X, Hisatome I, Yamamoto T, Huang J, Cheng J: High Uric Acid Activates the ROS-AMPK Pathway, Impairs CD68 Expression and Inhibits OxLDL-Induced Foam-Cell Formation in a Human Monocytic Cell Line, THP-1 Cell Physiol Biochem 2016 40:538-548.

44 Li Z, Shen Y, Chen Y, Zhang G, Cheng J, Wang W: High Uric Acid Inhibits Cardiomyocyte Viability Through the ERK/P38 Pathway via Oxidative Stress. Cell Physiol Biochem 2018;45:1156-1164.

45 Amaro S, Planas AM, Chamorro A: Uric acid administration in patients with acute stroke: a novel approach to neuroprotection. Expert Rev Neurother 2008;8:259-270.

46 Onetti Y, Dantas AP, Pérez B, Cugota R, Chamorro A, Planas AM, Vila E, Jiménez-Altayó F: Middle cerebral artery remodeling following transient brain ischemia is linked to early postischemic hyperemia: a target of uric acid treatment. Am J Physiol Heart Circ Physiol 2015;308:H862-H874.

47 Nieto FJ, Iribarren C, Gross MD, Comstock GW, Cutler RG: Uric acid and serum antioxidant capacity: a reaction to atherosclerosis? Atherosclerosis 2000;148:131-139.

48 Ling P, Smith R, Bistrian B: Hyperglycemia enhances the cytokine production and oxidative responses to a low but not high dose of endotoxin in rats. Crit Care Med 2005;33:1084-1089.

49 Kang DH, Park SK, Lee IK, Johnson RJ: Uric acid-induced C-reactive protein expression: implication on cell proliferation and nitric oxide production of human vascular cells. J Am Soc Nephrol 2005;16:3553-3562.

50 Hink HU, Santanam N, Dikalov S, McCann L, Nguyen AD, Parthasarathy S, Harrison DG, Fukai T: Peroxidase properties of extracellular superoxide dismutase: role of uric acid in modulating in vivo activity. Arterioscler Thromb Vasc Biol 2002 22:1402-1408.

51 Doehner W and Landmesser U: Xanthine oxidase and uric acid in cardiovascular disease: clinical impact and therapeutic options. Semin Nephrol 2011; 31:433-440.

-52 Choi H K, Atkinson K, Karlson E W, Willett W, Curhan G: Purine-rich foods, dairy and protein intake, and the risk of gout in men. N Engl J Med 2004;350:1093-1103. 